\title{
Study on Analytical Modelling of Tsunami Wave Propagation
}

\author{
Yasmin Regina $\mathrm{M}^{\mathrm{a}, 1}$ and Syed Mohamed $\mathrm{E}^{\mathrm{b}}$ \\ ${ }^{a}$ Deptof Civil Engineering, BSA Crescent Institute of Science and Technology, Chennai, \\ India \\ ${ }^{\mathrm{b}}$ Dept of CSE, BSA Crescent Institute of Science and Technology, Chennai, India
}

\begin{abstract}
Modelling of tsunami wave propagation plays a vital role in forecasting of disastrous tsunami. The earlier identification and prediction of tsunami provides more time for taking preventive measures and evacuation. On December 26, 2004, massive destruction of lives and properties due to tsunami increases the needs to develop a fast and accurate modelling of tsunami wave propagation. The modelling of waves provide the amplitude of tsunami, speed, arrival time and power of the wall of water and also run up distance and height. It also used to predict vulnerable buildings to tsunami. In this paper describes the modelling of tsunami wave propagation from generation to runup. Numerical and analytical methods used for modelling and simulation. Tsunami is serious of wave (wave train) which has a long wavelength $>500 \mathrm{~km}$ and celerity of wave more than $800 \mathrm{~km} / \mathrm{hr}$ in deep ocean and in shallow coast, their wavelength and celerity diminishes but the amplitude of wave increases above $30 \mathrm{~m}$. The scope of this study is to determine the areas which are going to hit by tsunami, amplitude of wave and their arrival time for early forecasting and alert the people within a short time after an earthquake happened.
\end{abstract}

Keywords.Modelling, simulation, propagation, forecasting.

\section{Introduction}

Tsunami is one of the most dangerous natural disaster which has a serious of powerful waves called wave train destroy everything in their way. Earthquake under the ocean bed or near the ocean cause tsunami. Earthquake is a rapid and sudden movement of earth by release of large amount of energy stored in rock materials of the earth's crust. Only the magnitude of earthquake greater than 7 can produce tsunami. Earth's lithosphere contained many plates which are locked together. These plates are moving millions of years because of this movement, the stress developed between the plates of rock materials. When the stress exceeds elastic strength of rock [1], enormous amount of energy released which is called earthquake. Not only earthquake, there are various factors are responsible for tsunami formation such as an underwater landslides, a volcanic eruption and very rarely meteorite strike.

During earthquake, there are three types of fault occur. They are Strike-slip fault, Normal fault and Reverse or Thrust fault. Lateral movement of earth with small vertical movement does not cause Tsunami.

\footnotetext{
${ }_{1}$ M. Yasmin Regina, Deptof Civil Engineering, BSA Crescent Institute of Science and Technology; E-mail: yasmin.regina92@gmail.com.
} 
Mostly, thrust faults are responsible for the tsunami. Fault plane solutions used for locating the epicenter, focal depth, fault area, strike, slip, dip and seismic moment (energy radiated from the earthquake) and Moment magnitude calculation. Richter Magnitude for greater earthquake lower estimates the effect of earthquake value. Moment magnitude gives the accurate earthquake measurement because it based on the rupture during earthquake. Slip considered as an important factor because it used for finding the depth of earth's crust move upward or amount of water displaced above the slide [3].

When tsunami is generated, the tsunami waves propagated in all direction. Tsunami waves propagate through Open Ocean as well as coastal areas. The tsunami can travel long distance with very less amount of energy lost. Long distance tsunami can cause a more damage to coastal areas. In Deep Ocean, there is a very little changes in wave height and these are barely noticeable when they reach shallow coast, the height of wave very high due to reducing velocity but the mass increases which increase the amplitude of wave. Now a days, there are various instrument used for recording sea bottom pressure, wave height and wave period etc. Tsunami early warning systems records the sea bed pressure change even in very small range and it transmits the information to buoys which records the small changes in wave height accurately and transmits the data to ground station through satellite.

\section{Methods}

Various Methods used for modelling of tsunami wave propagation. Analytical modelling of tsunami wave propagation, Mathematical equations derived from hydrodynamics of water useful for analyzing ocean waves during tsunami. Physical properties of ocean and water influence the wave propagation.

\subsection{Amplitude of Tsunami determination}

Ocean water is considered as an Incompressibe and inviscid fluid. The vertical velocity is neglected, it follows the wave equation,

$$
\frac{d^{2} y}{d t^{2}}=v^{2} \cdot \frac{d^{2} y}{d x^{2}}
$$

Where, $\mathrm{y}=$ water wave height, $\mathrm{V}=$ wave celerity, $\mathrm{x}=$ Cartesian coordinate and $\mathrm{t}=$ time.

$$
y=A \sin (k x-\omega t)
$$

Where, $\mathrm{A}=$ wave amplitude, $\mathrm{k}=$ wave number $=\frac{2 \pi}{\lambda}, \omega=$ angular frequency $=$ $\frac{2 \pi}{\mathrm{T}}, \lambda=$ wave length and $\mathrm{T}=$ wave period.

The sudden upliftment of earth displace the large amount of water above the fault area. The gravitational energy acts as a restoring force to make the water return to their place which is the reason for the tsunami wave generation. Gravitational energy 
converted to kinetic energy to make the entire depth of ocean water to flow. These restoration responsible for water to become a steady state after the generating force acts on it.

The wave height is proportional to the slip of the fault [2]. Tsunami early warning systems, DART buoys measure the wave height and wave period and transmit the information through satellite for every minute while tsunami. The height of tsunami wave increase as it approach to the shallow coast. Varying wave height can be determined by Green's law,

$$
H_{s}=\left[\frac{D_{d}}{D_{s}}\right]^{1 / 4} H_{d}
$$

Where, $\mathrm{Hd}=$ Height of water in deep ocean, Hs = height of water in shallow coast, $\mathrm{Dd}=$ depth of water in deep ocean from MSL and Ds $=$ Depth of water in shallow water.

In 2004, Indian Ocean tsunami, the wave height measured in the deep water is $600 \mathrm{~mm}$ (or $0.6 \mathrm{~m}$ ) by Radar Satellite recording. Assume the depth of deep water is $4000 \mathrm{~m}$. Using the above mathematical expression, the wave height measurement at various depths calculated. On 26th December, 2004 wave height observed at Marina beach, Chennai was $4.94 \mathrm{~m}$ [15].

Table 1. Relationship between Depth and Tsunami wave height

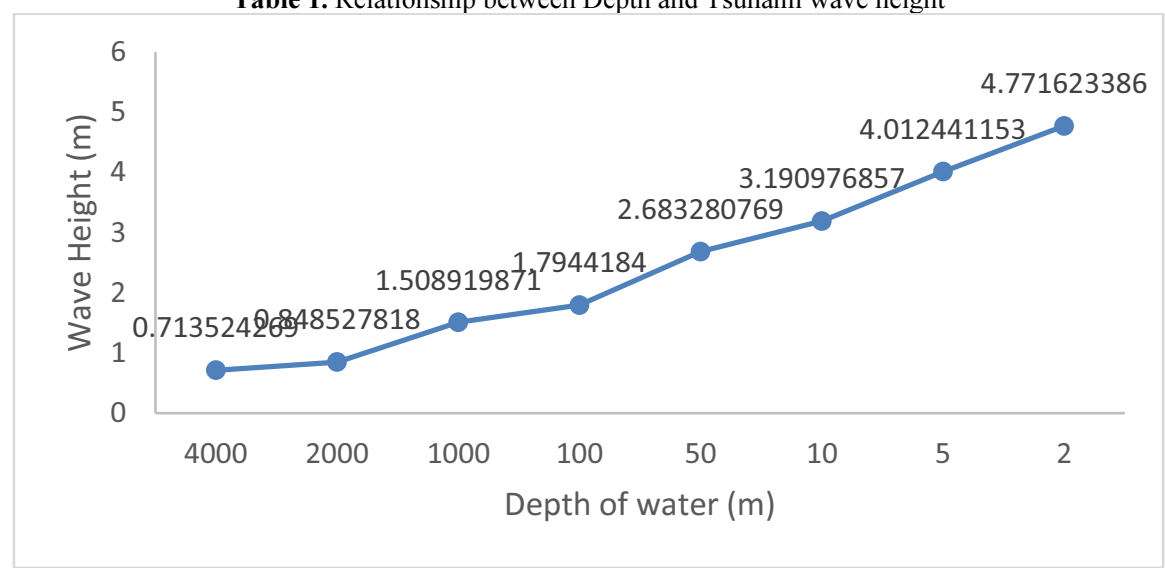

For a wave propagation perpendiculartowards straight coast with depth contours and parallel to the coast line then distant between rays ' $b$ ' is a constant. From Green's law for a sinusoidal wave, $V=$ velocity of wave and $\mathrm{h}=$ tsunami wave height.

$$
\mathrm{V} \mathrm{b} 1 / 2 \mathrm{~h} 3 / 4=\text { constant }
$$

The shallow water equation is a hyperbolic partial differential equation or parabolic if viscous shear is considered. The equation derived from the depth integrating Navier- Stokes equation. Horizontal length scale is much greater than 
vertical length scale. The flow is incompressible, inviscid and Newtonian fluid. The conservation of mass,

$$
\frac{d u}{d x}+\frac{d v}{d y}+\frac{d w}{d z}=0
$$

Where, $\mathrm{u}, \mathrm{v}, \mathrm{w}$ are velocity component in $\mathrm{x}, \mathrm{y}$ and $\mathrm{z}$ direction. The momentum equation,

$$
\frac{D V}{D t}=\mathrm{g}-\frac{1}{\rho} \nabla P+\nu \cdot \nabla^{2} \mathrm{~V}
$$

$\mathrm{V}=$ velocity, $\mathrm{g}=$ acceleration due to gravity, $\rho=$ density of water, $\mathrm{P}=$ Pressure and $v=$ kinematic viscosity.

The mass flow rate is same everywhere. Bernoullis equation relate the pressue, speed and height at two points in a incompressible, non-viscous flow condition by,

$$
\mathrm{P}+\frac{1}{2} \rho v^{2}+\rho g h=\text { constant }
$$

Pressure for tsunami waves, $\quad \mathrm{P}=\frac{1}{2} \mathrm{~g} \mathrm{~h}^{2}$

\subsection{Speed of the tsunami}

Speed of water waves depends on change in depth. In Deep Ocean, the wave speed is higher when it reaches shallow coast, the speed of wave diminishes but the wave height increases because of the increase in mass. Based on depth to length relation, the ocean is splitted into three parts, 1. Deep water, 2.Transition zone, 3. Shallow coast.

Deep Ocean, when depth $>$ L/2

$$
\mathrm{C}_{1}=\sqrt{g L / 2 \pi}
$$

Where, $\mathrm{L}=$ wavelength and $\mathrm{C}=$ speed of the wave.

For Transition zone, $\mathrm{L} / 2<$ depth $>\mathrm{L} / 20$

$$
\mathrm{C}_{2}=\sqrt{\frac{g L}{2 \pi} \tan \mathrm{h}\left(\frac{2 \pi h}{L}\right)}
$$

For shallow depth, depth $<\mathrm{L} / 20$

$$
\mathrm{C}_{3}=\sqrt{g h}
$$

$\mathrm{C} 1>\mathrm{C} 2>\mathrm{C} 3$, It shows the speed of wave in deep water is very high when compared to shallow water. Wave speed, $\mathrm{C}=\mathrm{L} / \mathrm{T}$.

Tsunami waves are not a single wave, they are a group of waves called wave train. The group wave velocity $(\mathrm{Cg})$ in deep water when compared to single wave phase velocity $(\mathrm{Cp})$, 


$$
\mathrm{C}_{\mathrm{g}}=\frac{1}{2} \mathrm{C}_{\mathrm{p}}
$$

But in shallow water, the group wave velocity is equal to the phase velocity.

$$
\mathrm{C}_{\mathrm{g}}=\mathrm{C}_{\mathrm{p}}
$$

Different magnitude of earthquake has various wave height. It influence the tsunami wave height and speed of the tsunami. If depth only considered for estimation, it gives almost same result for all types of earthquake. Therefore it leads to error.

When tsunami generated, it propagates all the direction like to shallow coast and also towards ocean. It can travel long distance and cause damage to lives. Therefore it is necessary to predict the tsunami propagation in all the direction.

\subsection{Travel time of tsunami}

Travel time (T) is calculated by the following formula [13] [14],

$$
\mathrm{T}=2 \mathrm{~L} /\left(\mathrm{C}_{1}+\mathrm{C}_{2}\right)
$$

Where, $\mathrm{C} 1, \mathrm{C} 2=$ speed of waves at $1 \& 2$ location and the Cvalues calculated based on the depth given in above. $\mathrm{L}=$ Length between the location $1 \& 2$.

$$
\mathrm{L}=\mathrm{R} \operatorname{arc} \cos \left(\operatorname{Sin} \varphi_{1} \operatorname{Sin} \varphi_{2}+\operatorname{Cos} \varphi_{1} \operatorname{Cos} \varphi_{2} . \operatorname{Cos} \Delta \Psi\right)
$$

$\mathrm{R}=$ Earth's radius $=6371.2 \times 10^{3} \mathrm{~m}$

$\varphi_{\mathrm{A}}, \varphi_{\mathrm{B}}=$ Latitudes of the location $1 \& 2$

$\Delta \Psi=$ difference between the longitudes of location $1 \& 2$.

In 2004, Indian Ocean tsunami, the travel time observed at coastline of Tamil Nadu 2 hrs and 30 minutes after the generation of tsunami [15]. If the tsunami travel from a long distance causes major effects to the coastline.

\section{Conclusion}

This paper shows the review of general analytical modelling of Tsunami propagation. The height of tsunami wave and energy increases from deep ocean to shallow water. These energy of wall of water causes the damage. The research is going on to predict the tsunami propagation all the direction and get accurate results by combining numerical, analytical approach and cellular automata which is one of the tool used for wave propagation in all direction. The scope of this study is to determine amplitude of tsunami wave and their arrival time within in short time with great accuracy for helping the society to save from the disastrous tsunami.

\section{Acknowledgement}

We would like to thank this research paper work has been supported by DST-SERB project ref. no. CRG/2018/002022/MS in the project title on "CELLULAR AUTOMATA MODEL FOR PROPAGATION OF TSUNAMI WAVE”. 


\section{Reference}

[1] Wu X W et al., Physical Mechanism of Major Earthquakes by Earthquake Cases Analysis, Chinese Journal of Geophysics, Vol.59, No.6, 2016, pp: 658-675.

[2] N. A. Haskell, Elastic displacements in the near-field of a propagating fault, Bull. Seism. Soc. Am., 59:865-908, 1969

[3] Geist, E.L., and Yoshioka, S., Source parameters controlling the generation and propagation of potential local tsunamis along the Cascadia margin, Natural Hazards, v. 13, p. 151-177, 1996.

[4] Wu X W et al., Physical Mechanism of Major Earthquakes by Earthquake Cases Analysis, Chinese Journal of Geophysics, Vol.59, No.6, 2016, pp: 658-675.

[5] V. Yuvaraj, s. Rajasekaran and e. Syed mohamed, An Alternative Analytical Model for Propagation of Tsunami Waves, international journal of pure and applied mathematics volume 113 no. 62017 , $29-37$.

[6] YoshimitsuOkada, Simulated Empirical Law of Coseismic Crustal Deformation, J. Phys. Earth, 43, 697-713, 1995.

[7] Vince Cronin, A Draft Primer on Focal Mechanism Solutions for Geologists, 2004.

[8] Rick Salmon, Introduction to Ocean Waves, Scripps Institution of Oceanography, University of California, San Diego.

[9] Warren B. Hamilton, Driving mechanism and 3-D circulation of plate tectonics, Geological Society of America Special Paper 433, Chapter 1, 2007.

[10] Costas E. Synolakis, A Hydrodynamics Perspective for the 2004 Megatsunami, Geohazards, Engineering Conferences International, 2006.

[11] C. C. Mei,.WAVE PROPAGATION .1.138J/2.062J/18.376J, 2004, MIT.

[12] Emile A. Okaland Costas E. Synolakis, Sequencing of tsunami waves: why the first wave is not always the largest, Geophys. J. Int. (2016) 204, 719-735.

[13] Yu I. Shokin, L. B. Chubarov, V. A. Novikov, A. N. Sudakov, Calculations Of Tsunami Travel Times Charts In The Pacific Ocean (Models, Algorithms, Techniques, Results), The InternationalJournal of The Tsunami Society Volume 5 Number 2, 1987.

[14] Andrei G. Marchuk, Rules of application of algorithms for tsunami waves kinematic computations based on the Huygens principle, Bull. Nov. Comp. Center, Math. Model. In. Geophy., 5(1999), 93-103.

[15] R. Rajaraman, S. Joseph Winston, Numerical Simulation of Tsunamis on the Tamil Nadu Coast of India, Marine Geodesy, 29: 167-178, 2006. 